Ordered to take some warm wine; frictions with hot flannel to the surface, and bottles of hot water to the feet. By perseverance in these measures he was gradually roused from this state, appearing much more exhausted than usual. Tincture of opium 30 drops immediately; to have recourse to the wine and frictions should he fall into the same state again.

29. No recurrence of the fit since; slept tolerably ; his sufferings much increased, particalarly the pain in the region of the heart ; pulse 97 ; quick, with an occasional intermission. Twenty leeches to the left side; the colchicum draught immediately.

31. Great debility; petechiæ more numerous; has had some bleeding from the gums; pulse 100, quick and irregular ; bowels frely evacuated by means of the colchicum. Owing to the general state of the system I did not deem it prudent to repeat the leeches (which always bleed very freely and for a considerable time), though anxious to do so, being strongly impressed that there was inflammation of the pericardium still unsubdued. I therefore had recourse to counter-iritation by means of blisters or tartar emetic ointment, still continuing the colchicum as a purgative.

Nov. 3. Debility still very alarming; have remarked that during the last few days the paroxysms occurred periodically night and morning. Says he does not suffer so much during their continuance as formerly, though they last equally as long, and maintain all the characters as before described. Four grains of sulphate of quinine with 20 drops of sulphuric acid every night; the colchicum dranght every second day; blister to be dressed with savine ointment.

7. After taking the quinine for a few days the fits did not occur so regularly, which I attributed to its use; under this impression I continued its exhibition regularly with the colchicum and counter-irritation. Under this treatment he experienced a decided improvement; it was, therefore, followed up for sometime modified according to circumstances, and he still continued to improve, gradually regaining his strength; the paroxysms neither attacking him so often nor continuing so long, being more free from pain than he had been for several months previously, but his health was not sufficiently restored so as to enable him to resume his arduous employment for nearly three months subsequently.

On reviewing the foregoing symptoms, and considering the history of the case, I am inclined to attribute the cause of the affection for which I was consulted, to in. fammation of the pericardium transferred from the extremities to this membrane; and I am also of opinion that the paroxysms which attacked him generally twice a day, wese induced by irregular action of the heart caused by inflammation of its invest- ing membrane; that the acute stage of inflammation had subsided when the quinine was administered, $I$ am inclined to infer from the beneficial effects which attended its use at this stage of the disease; invigorating remedies were indicated, and might they not have acted by giving tone to the system generally, and thence enable the heart to perform its proper function with due regularity? That there was a hæmorrhagic tendency was very apparent from the numerous petechiæ before alluded to, and also from the fact that whenever there was a breach of surface, it was with considerable difficulty the oozing of the blood could be restrained. Was this state the consequence of deranged function of the centre of the circulation, or was it mere coincidence? I cannot answer the question, but I observed the fact that according as the inflammatory symptoms subsided, the petechiæ on the body diminished and finally disappeared altogether.

\section{STRAPPING THE HEAD IN CHRONIC} HYDROCEPHALUS.

\section{To the Editor of THE LANCET.}

SIR :-I see, by one of your July Numbers, that Dr. Engelmann has been trying my plan of strapping the head for the cure of chronic hydrocephalus, with success, in Germany. It is now nearly fifteen years since $I$ published my two first cases, in the " Medical Repository," one of which was copied into your first volume, and it has certainly rather surprised me that it has not been tried by any English practitioner since that time; at least, I have seen no published case; but $I$ suppose it was in consequence of the more brilliant plan by Dr. Conquest having been soon after submitted to the public. However, rather than run a trocar into the brains of my patients, with the uncertain success even of Dr. Conquest himself, I havel preferred adhering to my own plan, and that with invariable success in all cases wherein it was applicable; and I have taken care not to use it where the chances of a successful issue were but slight. I hope, that the publicatiou of Dr. Engelmann's cases will induce some of our own medical men to give the plan a trial. I should be happy to supply every information derived from my own experience. I am, Sir, yours \&c.

Bath, August 5, 1838. J. F. BARnard.

** Our correspondent has mainly to blame himself for the neglect into which his practice has fallen. If, as Mr. Barnard says, " he has employed the practice of bandaging with invariable success in all cases wherein it was applicable," he should place those cases upon record, and we will feel much pleasure in affording him the best means of giving them publicity. 